\title{
Determinants of fatigue and stress
}

\author{
Rüya D Kocalevent ${ }^{1 *}$, Andreas Hinz ${ }^{3}$, Elmar Brähler ${ }^{3}$ and Burghard F Klapp ${ }^{2}$
}

\begin{abstract}
Background: Fatigue can be triggered by previous perceived stress which may lead to impairment of performance and function. The purpose of the study was to investigate the relationship between fatigue and perceived stress.

Method: Health determinants including sociodemographic factors for associations between fatigue and perceived stress in the general population $(N=2,483)$ are outlined. Fatigue and stress were assessed with the Chalder Fatigue Scale (CFS) and the Perceived Stress Questionnaire (PSQ).

Results: Within the general population, $25.9 \%$ of male and $34.5 \%$ of female respondents reported moderate fatigue during the last six months; $9.7 \%$ of subjects reported substantial fatigue lasting six months or longer. An adjusted regression analysis $\left(R^{2}\right.$ corr $\left.=.28, p<.001\right)$ showed that fatigue is highest associated with perceived stress and self-perceived health status. The following factors were correlated with increased rates of fatigue and perceived stress: female gender, divorce/separation, low social class and poor health status.
\end{abstract}

Conclusion: We conclude that the two conditions overlap most in terms of socio-economic status and selfperceived health status.

Keywords: Fatigue, stress perception, epidemiology, health determinants

\section{Background}

Unexplained fatigue is a relatively common condition in the community and primary care [1].

A recent study in the Netherlands has reported a prevalence rate of fatigue up to $36.4 \%$ in the general population associated with unhealthy lifestyles or coping mechanisms [2]. That corresponds with results from the Eurobarometer Mental Health, where 26\% of the respondents from 27 European countries reported to be "tired most of the time" and only 51\% felt "full of energy" [3]. There are several studies showing that fatigue is associated with psychiatric morbidity, especially depression [1,4-7]. Yet fatigue can also be triggered by previous perceived stress which may lead to impairment of performance and function [8,9]. Higher self-reported stress in the premorbid period is associated with higher risk for chronic fatigue (odds ratios, 1.64-5.81) [10]. Stress, including psychological stress, can also have a biopsychosocial influence on fatigue [11]. A study of patients with chronic fatigue syndrome showed that the hypothalamo-pituitary-adrenal (HPA) axis component of

\footnotetext{
* Correspondence: kocalevent@medizin.uni-leipzig.de

'Department of Mental Health, University of Leipzig, Germany

Full list of author information is available at the end of the article
}

their stress response was dysfunctional [12]. But the nature of this association is still not clear.

In order to detect the relation of fatigue and perceived stress it can be argued what distinguishes perceived stress from anxiety and depression. In former studies recent perceived stress (last 4 weeks) could be distinguished from state but not from trait anxiety. In terms of depression results vary between $r=0.49-0.56$ [13-15].

To our knowledge, there have been only a few nationally representative studies of stress perception in the general population $[15,16]$. This lack is the result of several factors, including the challenge of operationalizing the relation or process of fatigue and stress perception. This paper reports findings from the Chalder-FatigueScale (CFS) and the PerceivedStress-Questionnaire (PSQ) in the general population. We aimed to:

(1) report the prevalence of fatigue and perceived stress, as well as associated sociodemographic risk factors in a nationally representative sample, and (2) determine the overlapping correlates of fatigue and perceived stress.

\section{Methods}

A nationwide survey representative of the German general population was conducted with the assistance of an
C Biomed Central

() 2011 Kocalevent et al; licensee BioMed Central Ltd. This is an open access article distributed under the terms of the Creative Commons Attribution License http://creativecommons.org/licenses/by/2.0, which permits unrestricted use, distribution, and reproduction in any medium, provided the original work is properly cited. 
institute certified for demographic research (USUMA, Berlin) according to the German law of data protection (\$30a BDSG) and with written consent. Previously ethics were weighted to the respective interests of the public and of the individuals concerned following $\$ 823$ (BGB) of the Civil Code of Law and in accordance with the guidelines in the Declaration of Helsinki. Age, gender, and educational level were the major criteria for representativeness according to the register of the 1994 Federal Elections. The response rate was nearly $80 \%$. The set of questionnaires was administered to the final sample of 2483 persons. In the first wave, attempts were made to contact 3125 persons. Two callbacks had to be without success before an address was considered a failure. The three-stage sampling procedure consisted of sample points in the first, household in the second, and persons in the third stage. Target households within the sample points were determined using the random-route procedure; the target persons within the households were selected using random digits. The basic population for the data collection is made up of the German population aged at least 16 years and living in private households. The data sets for individuals aged at least 18 years were used for the data evaluation.

\section{Assessment of Fatigue (CFS)}

The CFS was developed to measure the severity of fatigue [17] and has been used in several studies. The 11item scale was found to be reliable (Physical Fatigue: $r=$ 0.85; Mental Fatigue: $r=0.82$; Total Score: $r=0.89$ ) and valid. Fatigue is defined as a continuous dimension as opposed to a category. Response options include: $0=$ 'better than usual', $1=$ 'no more than usual', $2=$ 'worse than usual' and $3=$ 'much worse than usual'. Symptoms that are not related specifically to fatigue but that are associated with the chronic fatigue syndrome were not included since the intention was to produce a scale that measured fatigue specifically.

\section{Assessment of Perceived Stress (PSQ)}

The construct validity of the PSQ was tested within a structural regression model [18]. The German and international applications of the PSQ and descriptive indicators of the sample are described in greater detail elsewhere $[16,18]$. The PSQ includes 30 items that are assigned to seven scales (Harassment, Overload, Irritability, Lack of Joy, Fatigue, Worries and Tension). The items refer to the period of the last four weeks (recent version) and can be answered with a 4-point rating scale $(1=$ almost never, $2=$ sometimes, $3=$ often and $4=$ usually). The resulting PSQ Total Score was linearly transformed between 0 and 1 according to Levenstein et al. $(\mathrm{PSQ}=($ raw value -30$) / 90)$ [13]. The Cronbach's $\alpha$ value of the PSQ is high $(\alpha=0.93)$.

\section{Analytic strategy}

The prevalence rates that are presented here were calculated by an analysis of frequencies. Logistic regression (odds ratios and 95\% confidence intervals) was used to quantify the associations between fatigue, stress perception and their sociodemographic correlates. Linear regression was used to quantify the association between fatigue and perceived stress. The data were analyzed with SPSS (Version 18.0).

\section{Results}

\section{Description of the sample}

The 2,483 subjects who took part in the study were similar in sex distribution $(52.7 \%$ female $/ \mathrm{n}=1346$, $47.2 \% \mathrm{male} / \mathrm{n}=1206)$ to the original sample of $\mathrm{N}=$ 3125 with a mean age of 47.6 years (SD 18.0). 52.2\% were married, $24.4 \%$ single, $1.1 \%$ married but separated from the partner, and $22.1 \%$ divorced or widowed, and $14.5 \%$ were unemployed.

\section{Overall prevalence}

Among the general population, 9.7\% of individuals reported substantial fatigue lasting six months or longer; $25.9 \%$ of male and $34.5 \%$ of female respondents reported fatigue during the last 6 months.

The PSQ Mean Score was 0.30 (SD 0.15). Thus the cut-off score for moderate level of perceived stress was estimated to be $>0.45$ to $\leq 0.60$ and for high level 0.60 . By using the cut-off scores described below, the prevalence of perceived stress at a moderate level was estimated to be $14.5 \%$. The prevalence of perceived stress at high levels was $3.1 \%$.

\section{Relation between Perceived Stress and Fatigue}

Table 1 shows the correlation between fatigue and the seven scales of the PSQ. The total score of the CFS and the Fatigue subscale of the PSQ showed the highest association $(r=0.48)$, followed by the Lack Of Joy subscale $(r=0.39)$ and Tension subscale $(r=0.35)$. Except for the correlation between the total score of Physical Fatigue and Overload $(r=0.02)$, all of the scales were associated on a $\mathrm{p}<0.05$ level. A regression analysis $\left(\mathrm{R}^{2}\right.$ corr $\left.=.28, \mathrm{p}<.001\right)$ showed that fatigue is highest associated with perceived stress $(\beta=0.30)$ and self-perceived health status $(\beta=-0.27)$, adjusted for age, gender, marital-, socioeconomic-, and employment status.

\section{Sociodemographic and health related odds ratios of perceived stress and fatigue}

The significant sex differences were indicated in table 2: women have a higher risk of fatigue and higher rates of stress perception. Age had a different effect. The elderly 
Table 1 Correlation matrix for the CFS and the PSQ

\begin{tabular}{|c|c|c|c|c|c|c|c|c|c|c|c|}
\hline \multicolumn{5}{|c|}{2 Scales of Fatigue } & \multicolumn{7}{|c|}{7 Scales of the PSQ } \\
\hline & $\begin{array}{c}\text { Fatigue } \\
\text { Total }\end{array}$ & $\begin{array}{l}\text { Mental } \\
\text { Fatigue }\end{array}$ & $\begin{array}{l}\text { Physical } \\
\text { Fatigue }\end{array}$ & PSQ-Total & Harassment & Overload & Irritability & Lack of Joy & Worries & Tension & Fatigue \\
\hline $\begin{array}{l}\text { Fatigue } \\
\text { Total }\end{array}$ & 1.00 & $0.88^{* *}$ & $0.97^{* *}$ & $0.37^{* *}$ & $0.15^{* *}$ & $0.05^{*}$ & $0.26^{* *}$ & $0.39 * *$ & $0.32^{* *}$ & $0.35^{* *}$ & $0.48^{* *}$ \\
\hline $\begin{array}{l}\text { Mental } \\
\text { Fatigue }\end{array}$ & - & 1.00 & $0.73^{* *}$ & $0.33^{* *}$ & $0.16^{* *}$ & $0.07^{* *}$ & $0.23^{* *}$ & $0.34^{* *}$ & $0.29 * *$ & $0.31^{* *}$ & $0.38^{* *}$ \\
\hline $\begin{array}{l}\text { Physical } \\
\text { Fatigue }\end{array}$ & - & - & 1.00 & $0.35^{* *}$ & $0.12^{* *}$ & 0.02 & $0.24^{* *}$ & $0.38^{* *}$ & $0.29 * *$ & $0.33^{* *}$ & $0.48^{* *}$ \\
\hline
\end{tabular}

Correlation coefficient: Spearman's $r$.

${ }^{*} p<0.05$

${ }^{* *} \mathrm{p}<0.001$.

(over 61 years) had the highest risk of fatigue, while the maximum odds ratios for stress occur in those between the ages of 41 years and 60 years.

Marital status is significantly correlated to both fatigue and stress perception; being divorced or separated increases the probability of both. Employment status contributes only substantially to stress perception not to fatigue.
Respondents with a lower socioeconomic status have significantly higher risk for fatigue than those from middle or high social classes. Poorly rated health is strongly associated with both a high stress perception and fatigue.

\section{Discussion}

We conducted a large survey of fatigue and stress perception in the general population to investigate

Table 2 Sociodemographic and health related odds ratios of perceived stress and fatigue

\begin{tabular}{|c|c|c|c|c|c|c|}
\hline & Prevalence of Stress & Odds Ratios $^{1}$ & $95 \% \mathrm{Cl}$ & Prevalence of Fatigue & Odds Ratios & $95 \% \mathrm{Cl}$ \\
\hline & n (\%) & & & n (\%) & & \\
\hline \multicolumn{7}{|l|}{ Sex } \\
\hline Men & $8.5 \%$ & - & - & $25.5 \%$ & - & - \\
\hline Women & $11.2 \%$ & $1.25^{*}$ & $1.03-1.53$ & $33.7 \%$ & $1.49^{* *}$ & 1.24-1.78 \\
\hline \multicolumn{7}{|l|}{ Age } \\
\hline $16-40$ & $19.7 \%$ & 1.18 & $0.92-1.52$ & $19.6 \%$ & - & - \\
\hline $41-60$ & $22.2 \%$ & $1.37^{*}$ & $1.06-1.77$ & $31.3 \%$ & $1.87^{* *}$ & $1.48-2.36$ \\
\hline $61>$ & $17.2 \%$ & - & - & $42.0 \%$ & $2.97^{* *}$ & 2.37-3.73 \\
\hline \multicolumn{7}{|l|}{ Marital Status } \\
\hline Married & $\begin{array}{c}231 \\
17.7 \%\end{array}$ & - & - & $29.3 \%$ & $0.64^{* *}$ & $0.51-0.79$ \\
\hline Single & $\begin{array}{c}120 \\
19.8 \%\end{array}$ & 1.14 & $0.90-1.46$ & $21.6 \%$ & - & - \\
\hline Seperated/divored/widowed & $\begin{array}{c}139 \\
24.3 \% \\
\end{array}$ & $1.49^{* *}$ & $1.17-1.89$ & $39.5 \%$ & $1.57^{* *}$ & $1.27-1.95$ \\
\hline \multicolumn{7}{|l|}{ Employment status } \\
\hline Employed/Retired/Student & $18.9 \%$ & - & - & $29.9 \%$ & 1.05 & $0.71-1.41$ \\
\hline Unemployed & $30.6 \%$ & $1.89^{* *}$ & $1.34-2.66$ & $29.8 \%$ & - & - \\
\hline \multicolumn{7}{|l|}{ Socioeconomic status (SES) ${ }^{2}$} \\
\hline Low & $22.3 \%$ & $1.38^{*}$ & $1.12-1.72$ & $34.9 \%$ & $2.32^{* *}$ & $1.56-3.44$ \\
\hline Medium & $17.3 \%$ & - & - & $28.0 \%$ & - & - \\
\hline High & $18.0 \%$ & 1.05 & $0.70-1.58$ & $30.8 \%$ & $0.43^{* *}$ & $0.29-0.64$ \\
\hline \multicolumn{7}{|l|}{ Self-perceived health status ${ }^{3}$} \\
\hline poor & $40.6 \%$ & $4.06^{* *}$ & $3.07-5.37$ & $68.8 \%$ & $9.38^{* *}$ & $7.04-12.50$ \\
\hline average & $30.4 \%$ & $2.56^{* *}$ & $2.02-3.33$ & $48.7 \%$ & $4.05^{* *}$ & $3.21-5.10$ \\
\hline good & $14.4 \%$ & - & - & $19.0 \%$ & - & - \\
\hline
\end{tabular}

Logist. Regression, Stress $\downarrow$ (PSQ $<0,30$ ) vs. Stress $\uparrow$ (PSQ $>0,30)$, Fatigue $\downarrow$ ( $<6$ months) vs. Fatigue $\uparrow$ ( 6 months)

${ }^{*} \mathrm{p}<0.05$

${ }^{* *} \mathrm{p}<0.001$

2 Winkler and Stolzenberg (1999)

${ }^{3}$ Indicator generated by single-item: „How content are you about your health status?"; poor: not content at all; average: depends; good: content-very content. 
sociodemographic correlates and the relation between fatigue and perceived stress. Furthermore, this paper presented the prevalence rates of both fatigue and perceived stress according to age and gender. The study showed that perceived stress and fatigue are related constructs. We found a notable association between fatigue and stress. The highest relationship could be detected between fatigue, tension and lack of joy. We conclude that fatigue and stress seem to share overlapping correlates and that aspects of these constructs seem to overlap. Common risk factor patterns could be identified according to socio-economic status and self-perceived health status: the lower the health status the higher the risk for stress and fatigue.

The relation of perceived stress (measured with the PSQ) and psychiatric morbidity was reported elsewhere (3-7) and was not included in the underlying study. Yet it could have helped to distinguish perceived stress from psychiatric morbidity and thus is a limitation of the study.

Studies of fatigue in the past have been based in clinical settings. The high prevalence rates of fatigue support the notion of a continuum of fatigue, as suggested by data from studies in clinical settings [19-25]. In our survey, $25.9 \%$ of male and $34.5 \%$ of female respondents reported fatigue during the last six months, and $9.7 \%$ of the general population reported substantial fatigue lasting six months or longer. These findings confirm the importance of fatigue as a symptom in the general population [2]. The trend of fatigue over a lifetime seems to be linear, while stress perception appears to be bell-shaped.

As in comparable studies, women report higher fatigue than men $[21,26]$. Other correlates of fatigue have not been reported before; employment status plays no significant role and higher social class lowers the risk of fatigue. A study of functional limitations of fatigued patients in Dutch general practices concluded that limitations from fatigue are rather unspecific and are related to "poor overall health"[2].

\section{Conclusion}

Elevated fatigue and perceived stress overlap most in terms of: low socioeconomic status and poor self-perceived overall health. Fatigue could be a stress-related disorder triggered by long lasting tension. Therefore, this relation deserves more research attention, particularly with regard to unexplained fatigue.

\section{Author details}

${ }^{1}$ Department of Mental Health, University of Leipzig, Germany. ${ }^{2}$ Department of Psychosomatis, Charité University Medicine Berlin, Germany. ${ }^{3}$ Department of Medical Psychology and Medical Sociology, University of Leipzig, Germany.

\section{Authors' contributions}

RK participated in the study design, performed statistical analysis and drafted the manuscript. AH participated in the study design and advised for analysis. EB participated in the sequence alignment and acquisition of data. BK conceived of the study, and participated in its design and coordination. All authors read and approved the final manuscript.

The nationwide survey was conducted with the assistance of an institute specialized for demographic research (USUMA, Berlin) which could provide a statement of approval and informed consent for publication from the persons form the general population who participated in the study. A copy of the written consent is available for review by the Editor-in Chief of BMC Research Notes. No experimental research took place in the study.

\section{Competing interests}

The authors declare that they have no competing interests.

Received: 24 March 2011 Accepted: 20 July 2011

Published: 20 July 2011

\section{References}

1. Skapinakis $P$, Lewis $G$, Mavreas $V$ : Unexplained fatigue syndromes in a multinational primary care sample: specificity of definition and prevalence and distinctiveness from depression and generalized anxiety. Am J Psychiatry 2003, 160:785-787.

2. van't Leven M, Zielhuis GA, van der Meer JW, Verbeek AL, Bleijenberg G: Fatigue and chronic fatigue syndrome-like complaints in the general population. Eur J Public Health 2009, 20:251-257.

3. European Commission. Special Eurobarometer 345 Mental Health 2010.

4. Skapinakis $P$, Lewis $G$, Meltzer $H$ : Clarifying the relationship between unexplained chronic fatigue and psychiatric morbidity: results from a community survey in Great Britain. Int Rev Psychiatry 2003, 15:57-64.

5. Skapinakis $P$, Lewis $G$, Mavreas $V$ : Cross-cultural differences in the epidemiology of unexplained fatigue syndromes in primary care. $\mathrm{Br} \mathrm{J}$ Psychiatry 2003, 182:205-209.

6. Skapinakis $P$, Lewis G, Mavreas V: One-year outcome of unexplained fatigue syndromes in primary care: results from an international study. Psychol Med 2003, 33:857-866.

7. Skapinakis $P$, Lewis $G$, Mavreas $V$ : Temporal relations between unexplained fatigue and depression: longitudinal data from an international study in primary care. Psychosom Med 2004, 66:330-335

8. Harvey SB, Wessely S: Chronic fatigue syndrome: identifying zebras amongst the horses. BMC Med 2009, 7:58

9. Maes M, Twisk FN: Chronic fatigue syndrome: Harvey and Wessely's (bio) psychosocial model versus a bio(psychosocial) model based on inflammatory and oxidative and nitrosative stress pathways. BMC Med 2010, 8:35

10. Kato K, Sullivan PF, Evengard B, Pedersen NL: Premorbid predictors of chronic fatigue. Arch Gen Psychiatry 2006, 63:1267-1272.

11. Hauser W, Stallmach A, Kocalevent RD, Rose M, Fliege H: Biopsychosocial predictors of fatigue in quiescent and mild ulcerative colitis - an explorative study. Psychosoc Med 2005, 2:Doc07.

12. Cleare AJ, Wessely SC: Chronic fatigue syndrome: a stress disorder? Br J Hosp Med 1996, 55:571-574.

13. Levenstein S, Prantera C, Varvo V, Scribano ML, Berto E, Luzi C, et al: Development of the Perceived Stress Questionnaire: A new tool for psychosomatic research. Journal of Psychosomatic Research 1993, 37:19-32.

14. Sanz-Carrillo C, Garcia-Campayo J, Rubio A, Santed M, Montoro M: Validation of the Spanish version of the Perceived Stress Questionnaire (PSQ). Journal of Psychosomatic Research 2002, 52:167-172.

15. Bergdahl J, Bergdahl M: Perceived stress in adults: prevalence and association of depression, anxiety and medication in a Swedish population. Stress and Health 2002, 18:235-241.

16. Kocalevent RD, Hinz A, Fliege H, Klapp BF: Regional and Individual Factors of Stress Experience in Germany. Das Gesundheitswesen 2010.

17. Chalder T, Berelowitz G, Pawlikowska T, Watts L, Wessely S, Wright D, et al Development of a fatigue scale. J Psychosom Res 1993, 37:147-153.

18. Kocalevent RD, Levenstein S, Fliege H, Schmid G, Hinz A, Brahler E, et al: Contribution to the construct validity of the Perceived Stress Questionnaire from a population-based survey. J Psychosom Res 2007, 63:71-81. 
19. Lewis $\mathrm{G}$, Wessely $\mathrm{S}$ : The epidemiology of fatigue: more questions than answers. J Epidemiol Community Health 1992, 46:92-97.

20. Kroenke K, Wood DR, Mangelsdorff AD, Meier NJ, Powell JB: Chronic fatigue in primary care. Prevalence, patient characteristics, and outcome. JAMA 1988, 260:929-934.

21. Chen MK: The epidemiology of self-perceived fatigue among adults. Prev Med 1986, 15:74-81.

22. Ridsdale L, Evans A, Jerrett W, Mandalia S, Osler K, Vora H: Patients who consult with tiredness: frequency of consultation, perceived causes of tiredness and its association with psychological distress. Br J Gen Pract 1994, 44:413-416.

23. Euba R, Chalder T, Deale A, Wessely S: A comparison of the characteristics of chronic fatigue syndrome in primary and tertiary care. $\mathrm{Br} J$ Psychiatry 1996, 168:121-126

24. Kenter EG, Okkes IM, Oskam SK, Lamberts H: Once tired, always tired? Limitations in function over time of tired patients in Dutch general practice. Eur J Gen Pract 2007, 13:67-74.

25. David A, Pelosi A, McDonald E, Stephens D, Ledger D, Rathbone R, et al Tired, weak, or in need of rest: fatigue among general practice attenders. BMJ 1990, 301:1199-1202.

26. Pawlikowska T, Chalder T, Hirsch SR, Wallace P, Wright DJ, Wessely SC: Population based study of fatigue and psychological distress. BMJ 1994, 308:763-766.

doi:10.1186/1756-0500-4-238

Cite this article as: Kocalevent et al:: Determinants of fatigue and stress. BMC Research Notes 2011 4:238.

\section{Submit your next manuscript to BioMed Central} and take full advantage of:

- Convenient online submission

- Thorough peer review

- No space constraints or color figure charges

- Immediate publication on acceptance

- Inclusion in PubMed, CAS, Scopus and Google Scholar

- Research which is freely available for redistribution

Submit your manuscript at www.biomedcentral.com/submit 